\title{
Solid-Phase Synthesis of Oligoester Ion Channels
}

\author{
Thomas M. Fyles*, Chi-Wei Hu, Horace Luong
}

Department of Chemistry, University of Victoria, Victoria, British Columbia, Canada, V8W 3P6

$$
\text { tmf@uvic.ca }
$$

Table of Contents

General Experimental $\quad$ S2

${ }^{1} \mathrm{H}$ NMR of 8

${ }^{13} \mathrm{C}$ NMR of 8

${ }^{1} \mathrm{H}$ NMR of 9

${ }^{13} \mathrm{C}$ NMR of 9

${ }^{1} \mathrm{H}$ NMR of 12

${ }^{13} \mathrm{C}$ NMR of $\mathbf{1 2}$ S8

${ }^{1} \mathrm{H}$ NMR of $\mathbf{1 3}$ S9

${ }^{13} \mathrm{C}$ NMR of $\mathbf{1 3} \quad \mathrm{S} 10$

${ }^{1} \mathrm{H}$ NMR of $\mathbf{1 4}$

${ }^{13} \mathrm{C}$ NMR of $\mathbf{1 4} \quad \mathrm{S} 12$

${ }^{1} \mathrm{H}$ NMR of 15

${ }^{13} \mathrm{C}$ NMR of 15

${ }^{1} \mathrm{H}$ NMR of $\mathbf{1 6}$

${ }^{13} \mathrm{C}$ NMR of $\mathbf{1 6} \quad \mathrm{S} 16$

${ }^{1} \mathrm{H}$ NMR of $\mathbf{1 7} \quad \mathrm{S} 17$

${ }^{13} \mathrm{C}$ NMR of $\mathbf{1 7} \quad \mathrm{S} 18$

${ }^{1}$ H NMR of $\mathbf{1 8} \quad$ S19

${ }^{13}$ C NMR of 18 
$\begin{array}{ll}{ }^{1} \mathrm{H} \text { NMR of } \mathbf{1 9} & \mathrm{S} 21 \\ { }^{13} \mathrm{C} \text { NMR of } \mathbf{1 9} & \mathrm{S} 22 \\ { }^{1} \mathrm{H} \text { NMR of } \mathbf{2 0} & \mathrm{S} 23 \\ { }^{13} \mathrm{C} \text { NMR of } \mathbf{2 0} & \mathrm{S} 24\end{array}$

General Methods. Unless specified, reagents were from commercial sources and were used without further purification. THF used for solid-phase reactions was dried over sodium and benzophenone and distilled. The Wang Resin had a loading capacity $0.75 \mathrm{meq} / \mathrm{g}$ (100-200 mesh). New resin is swollen and washed in THF before usage. Solid-phase reactions were carried out in $25 \mathrm{~mL}$ solid-phase reaction vessels and were agitated by a mechanical shaker. Column chromatography was performed on silica gel (grade 60, 63-200 mesh). Size exclusion separation of the oligoester compounds was performed on a Lipophilic Sephadex LH-20 column. All amounts for solid-phase reactions are for $200 \mathrm{mg}$ of resin. Yields for the solid-phase reactions are reported relative to their starting resin loading capacity. 


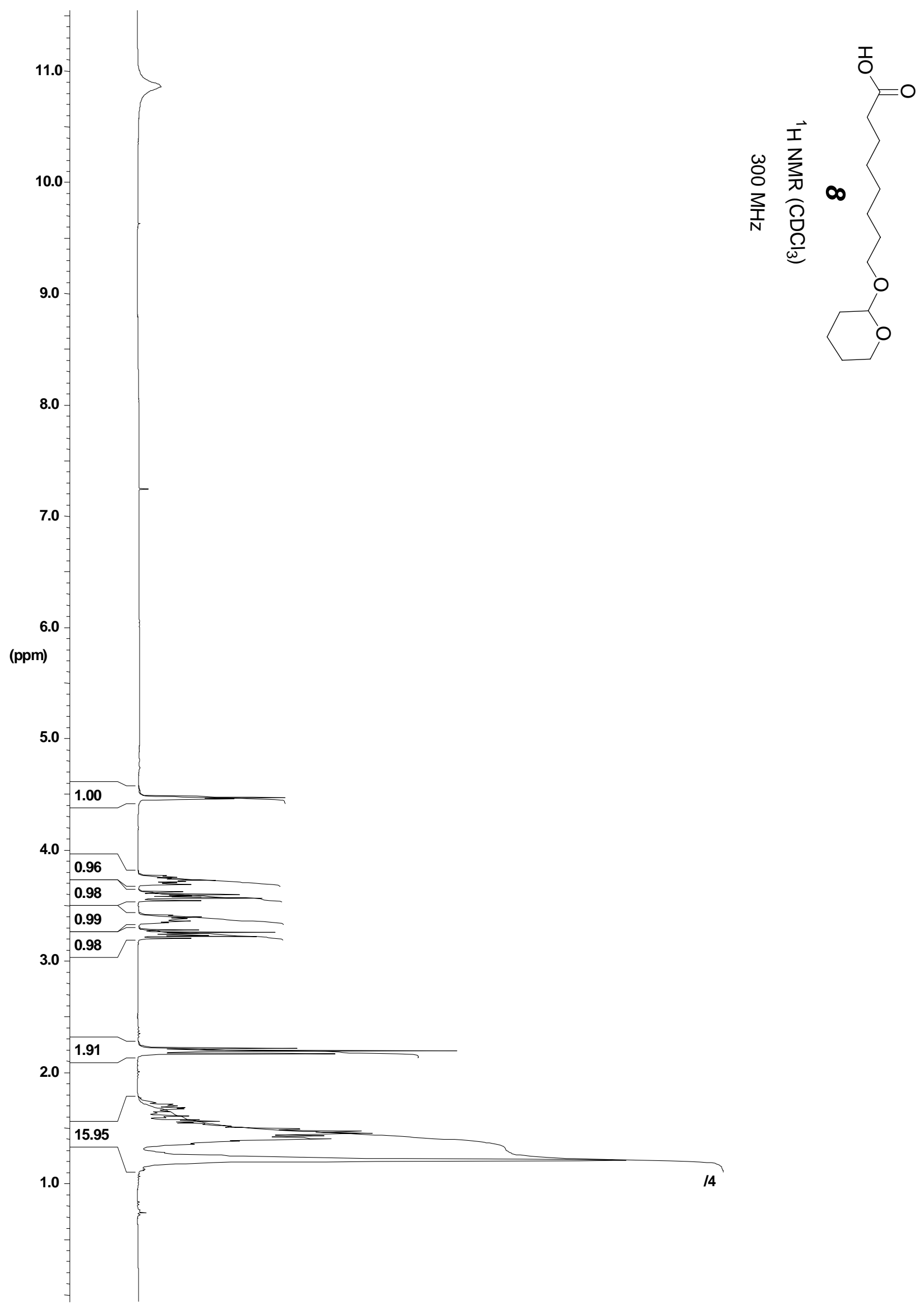




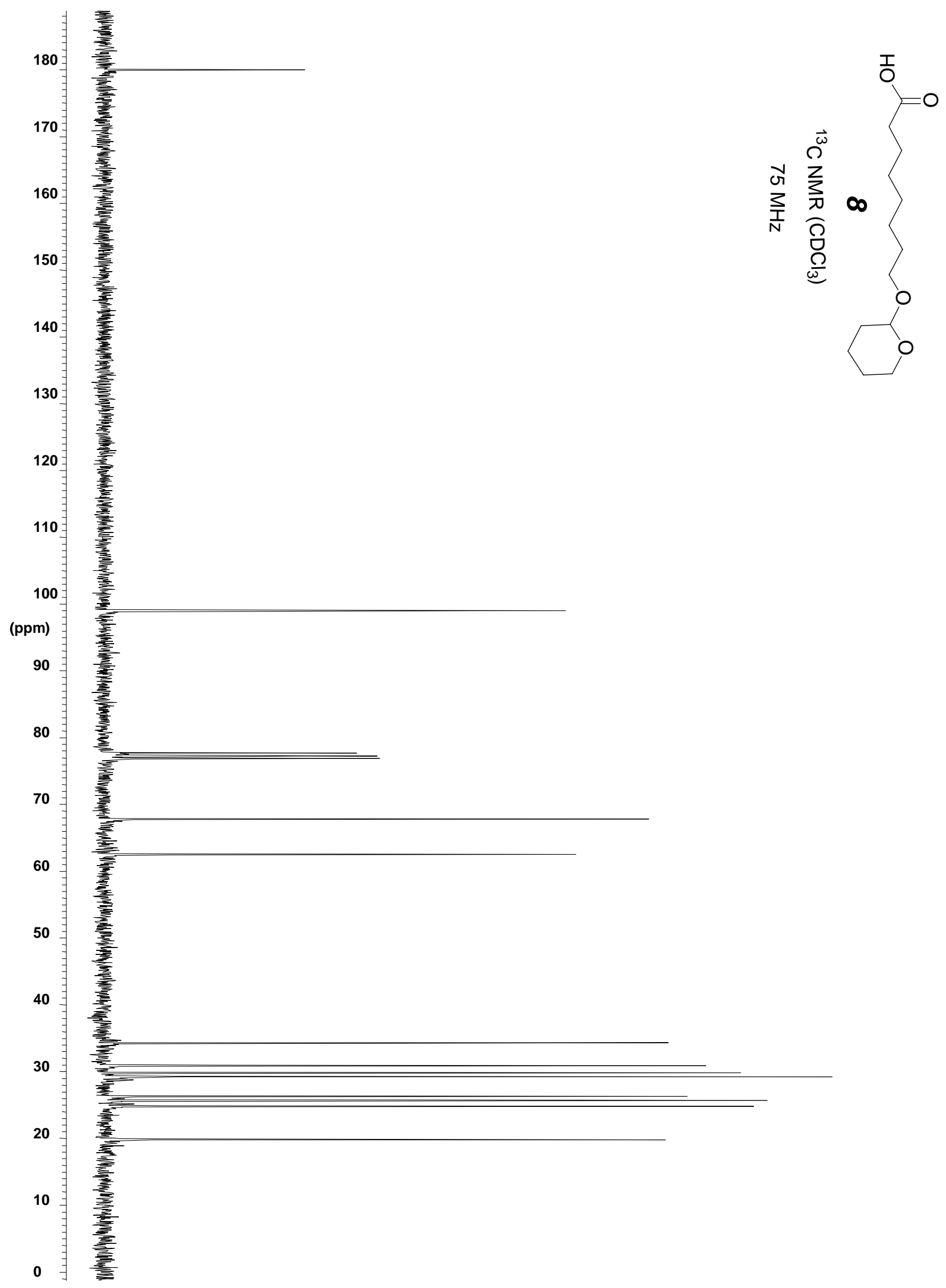




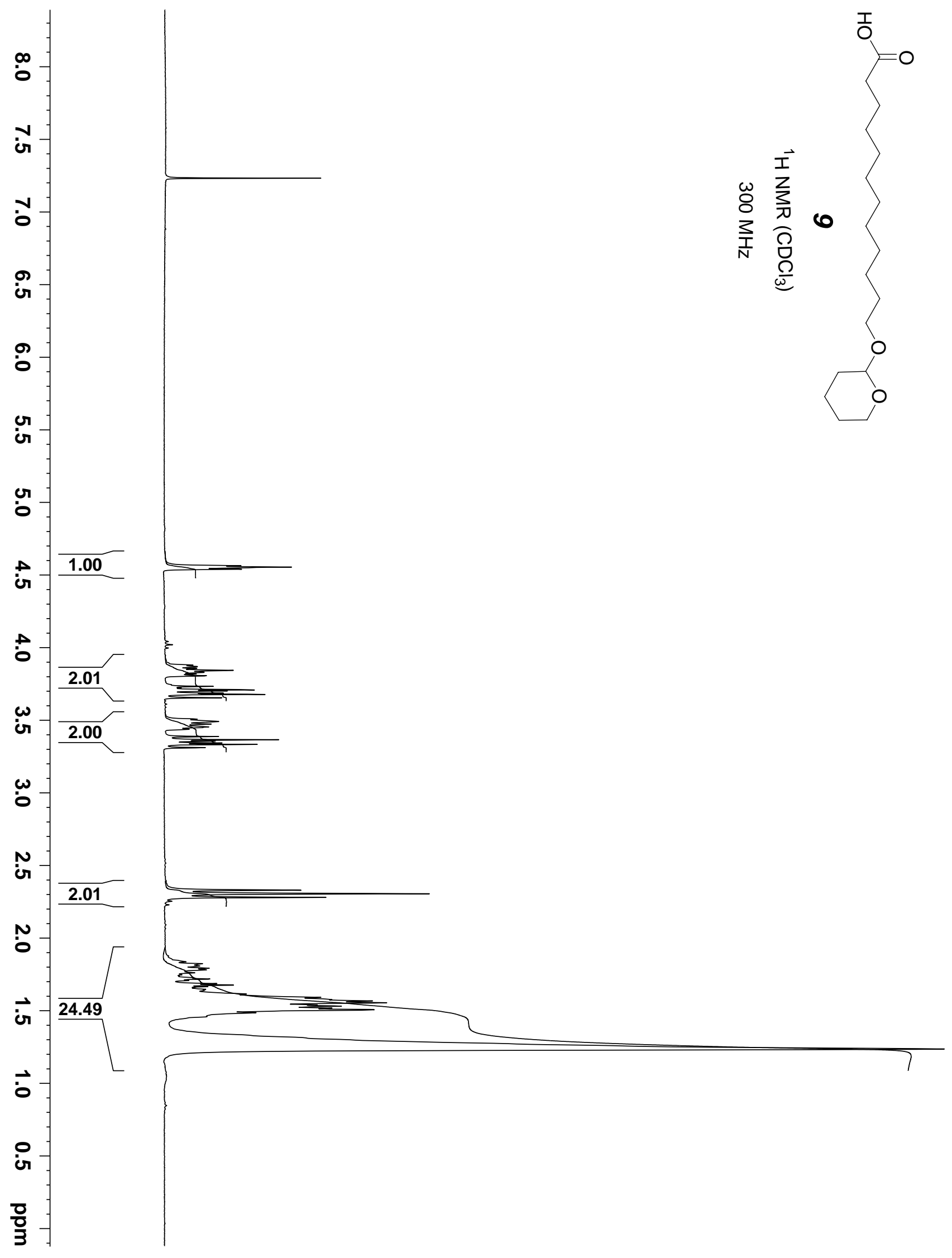




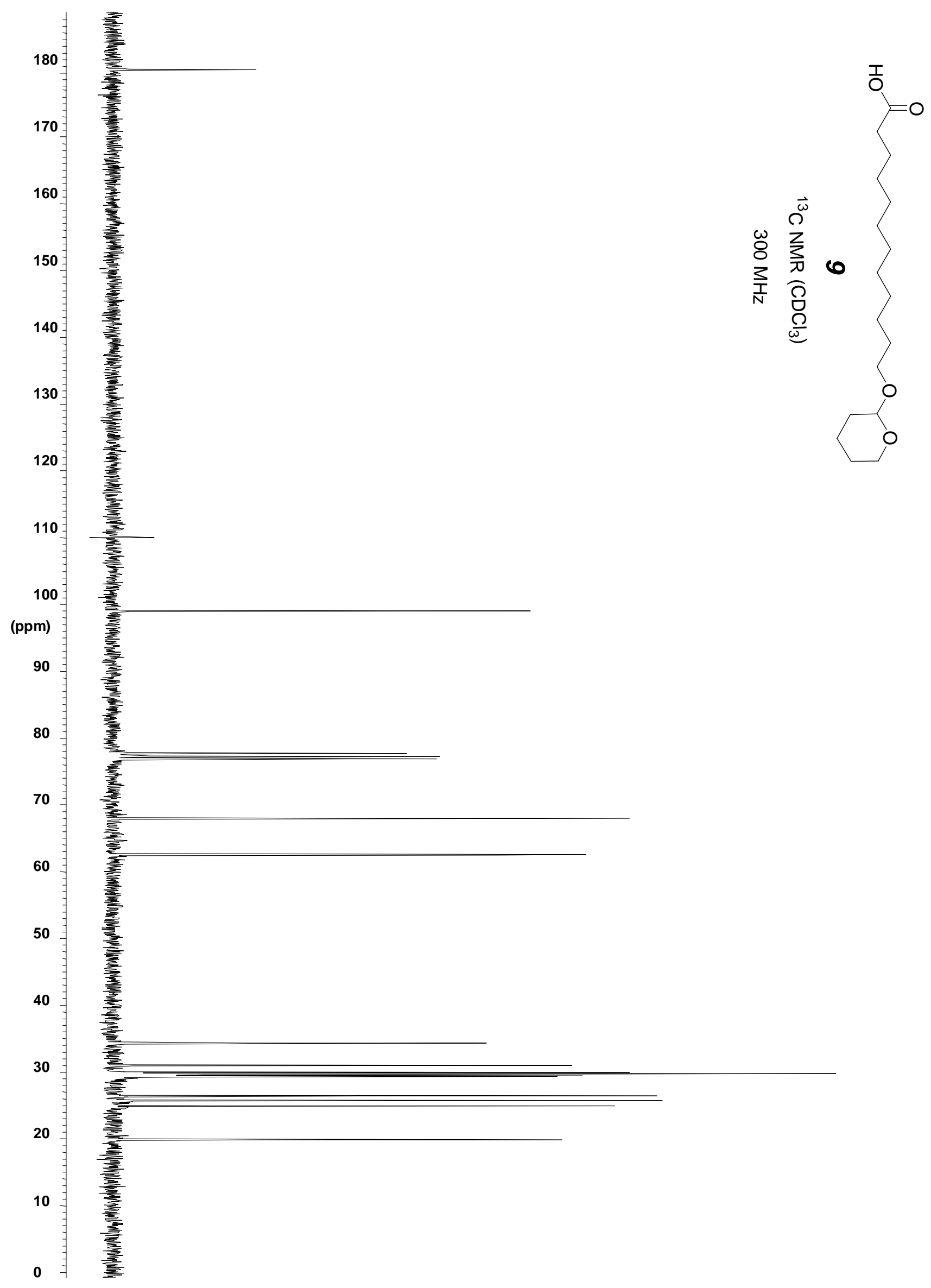




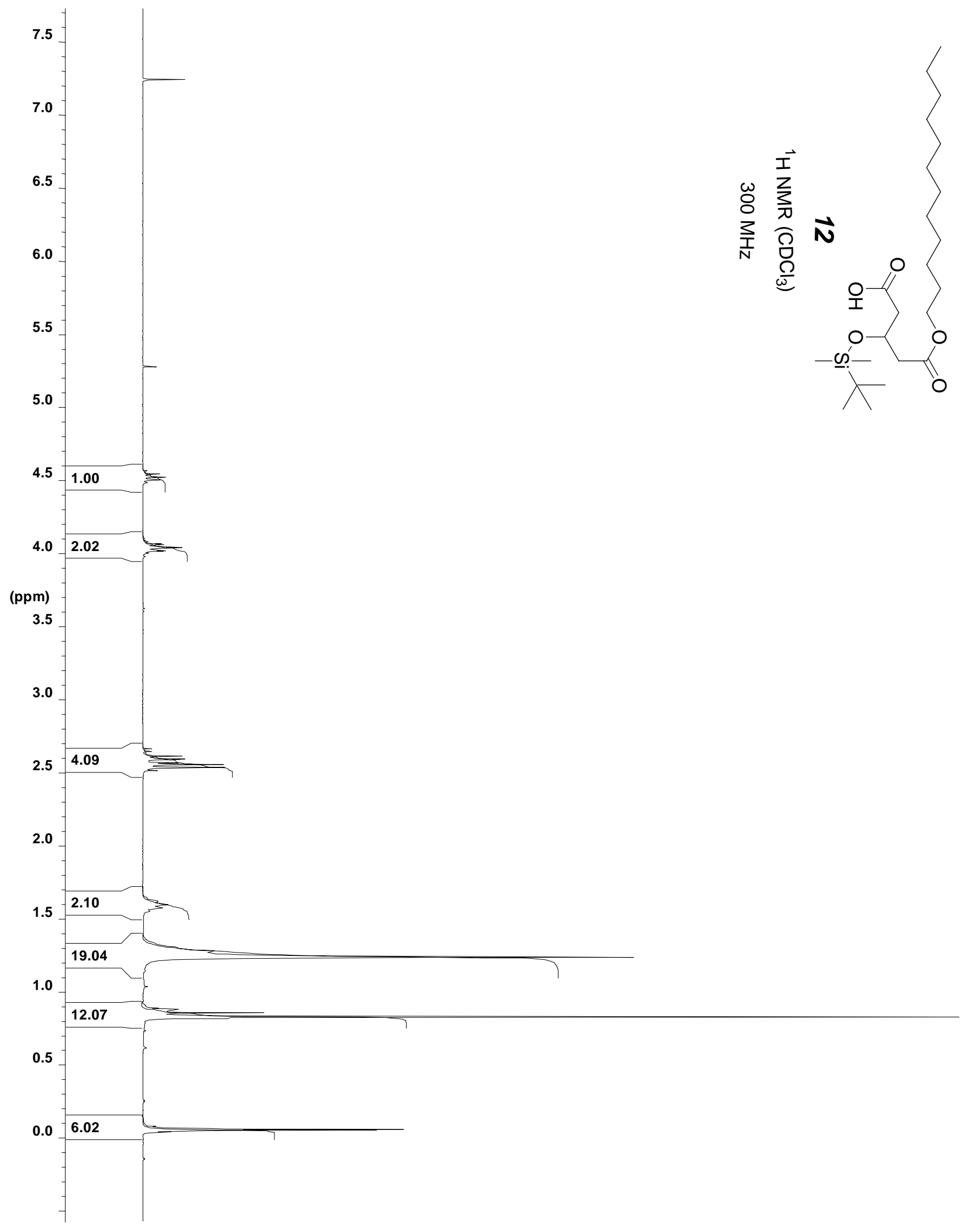




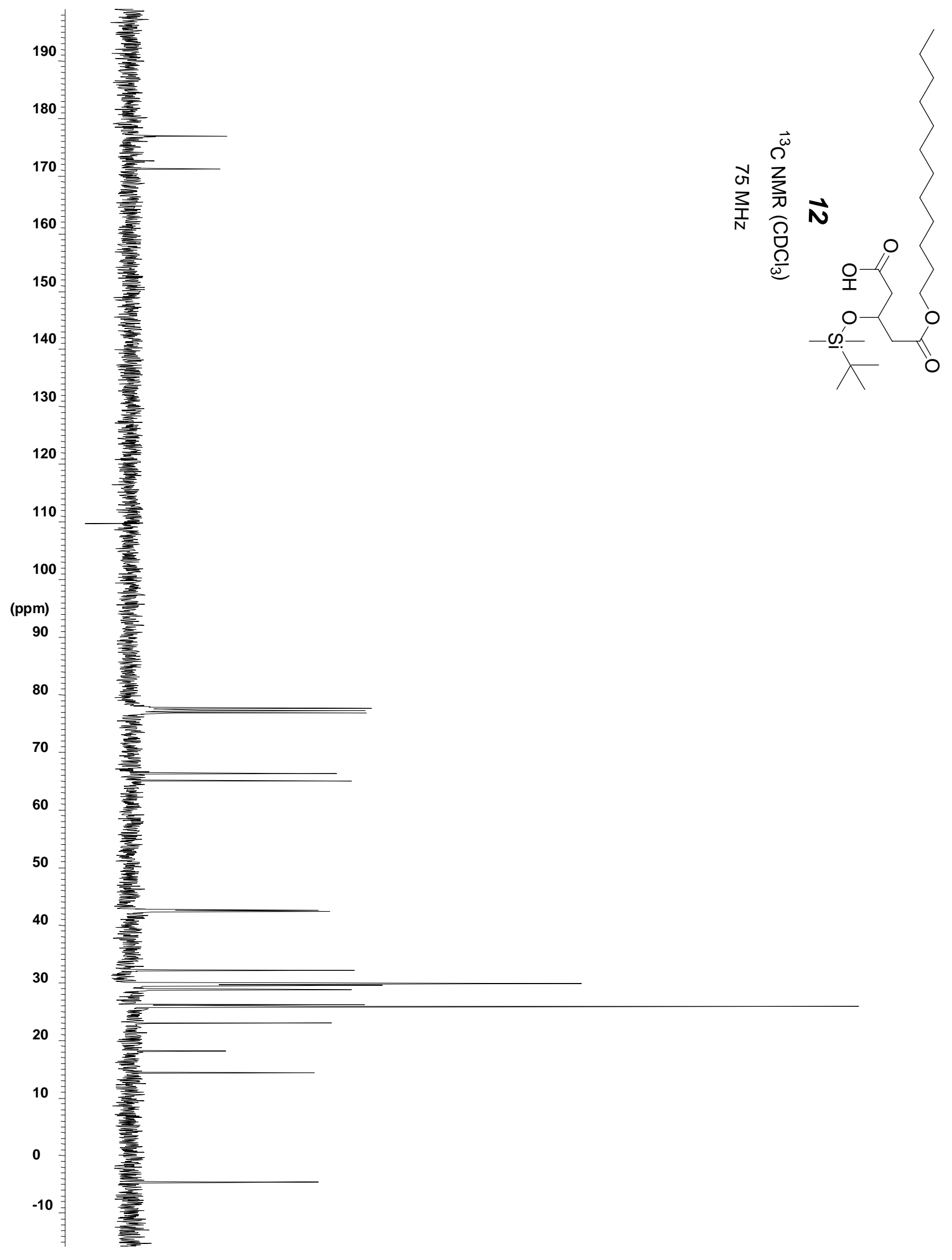




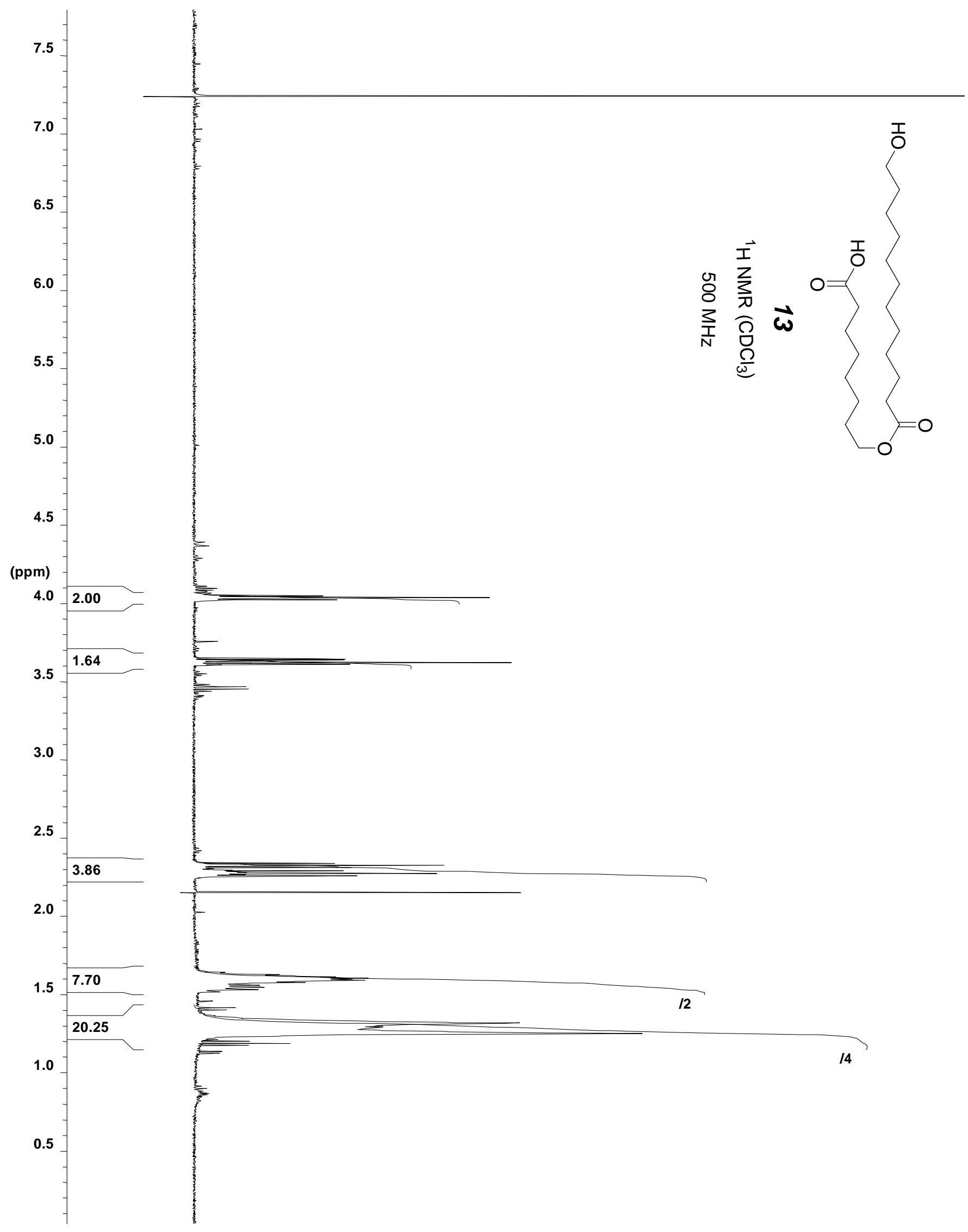




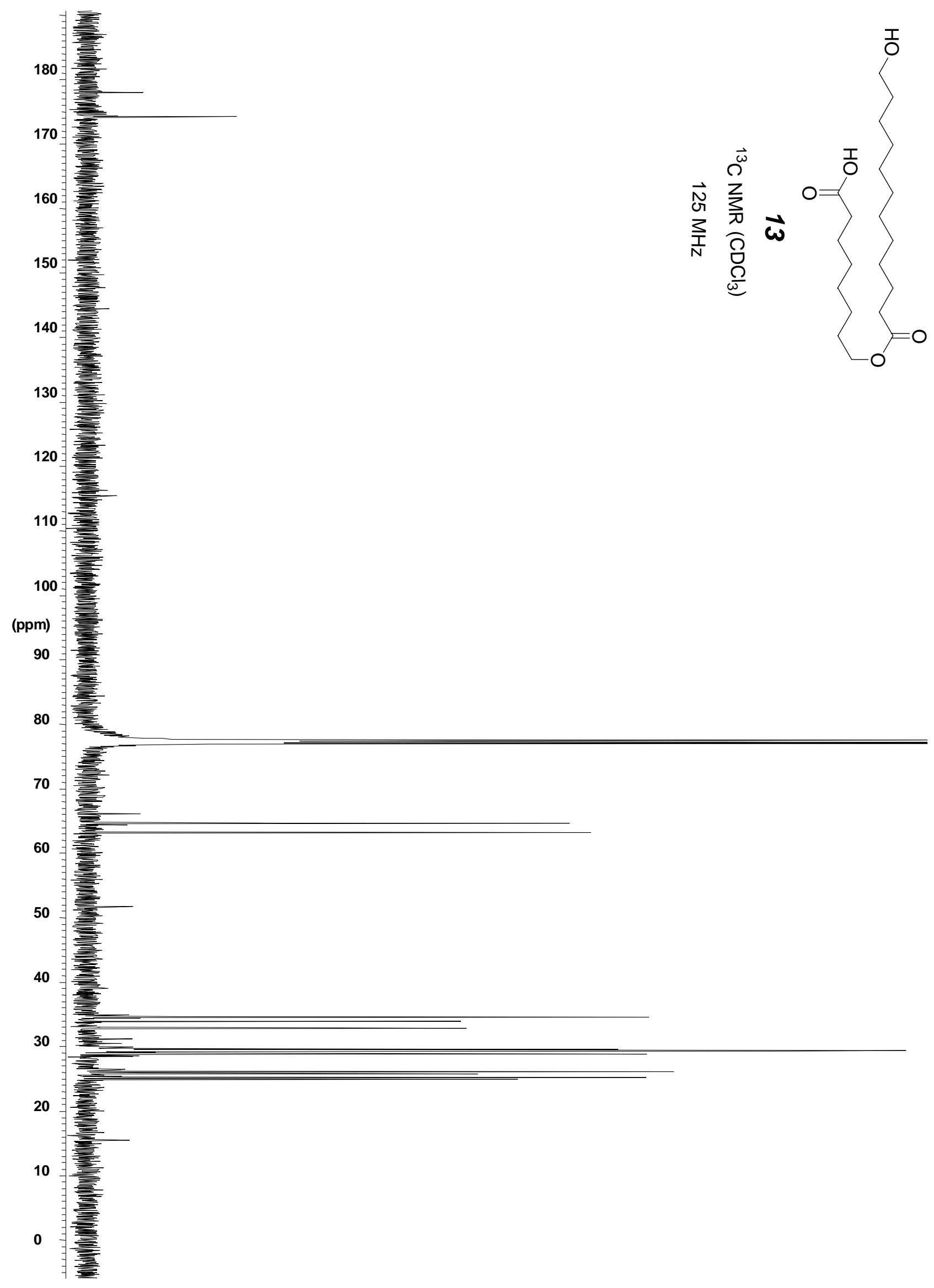




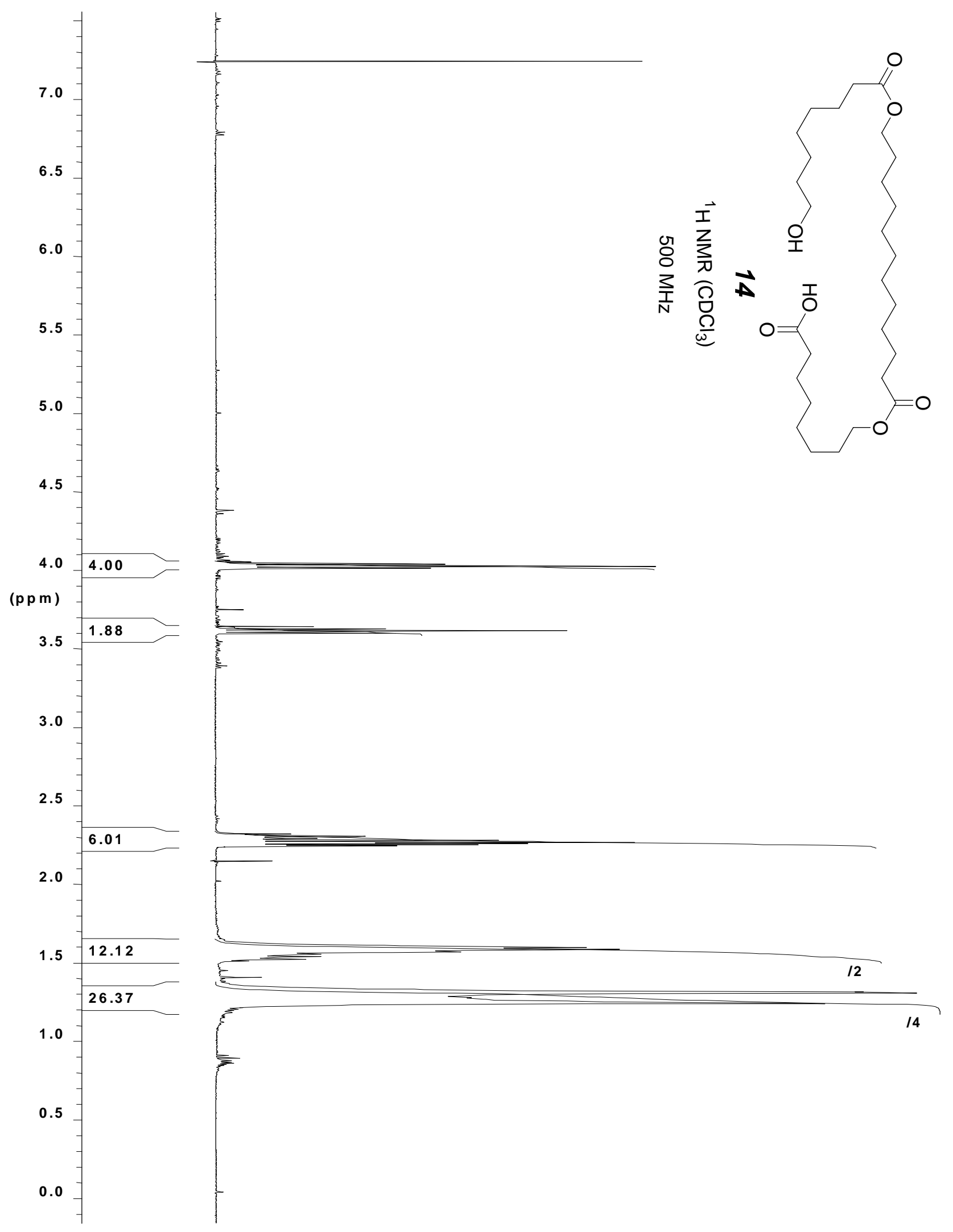




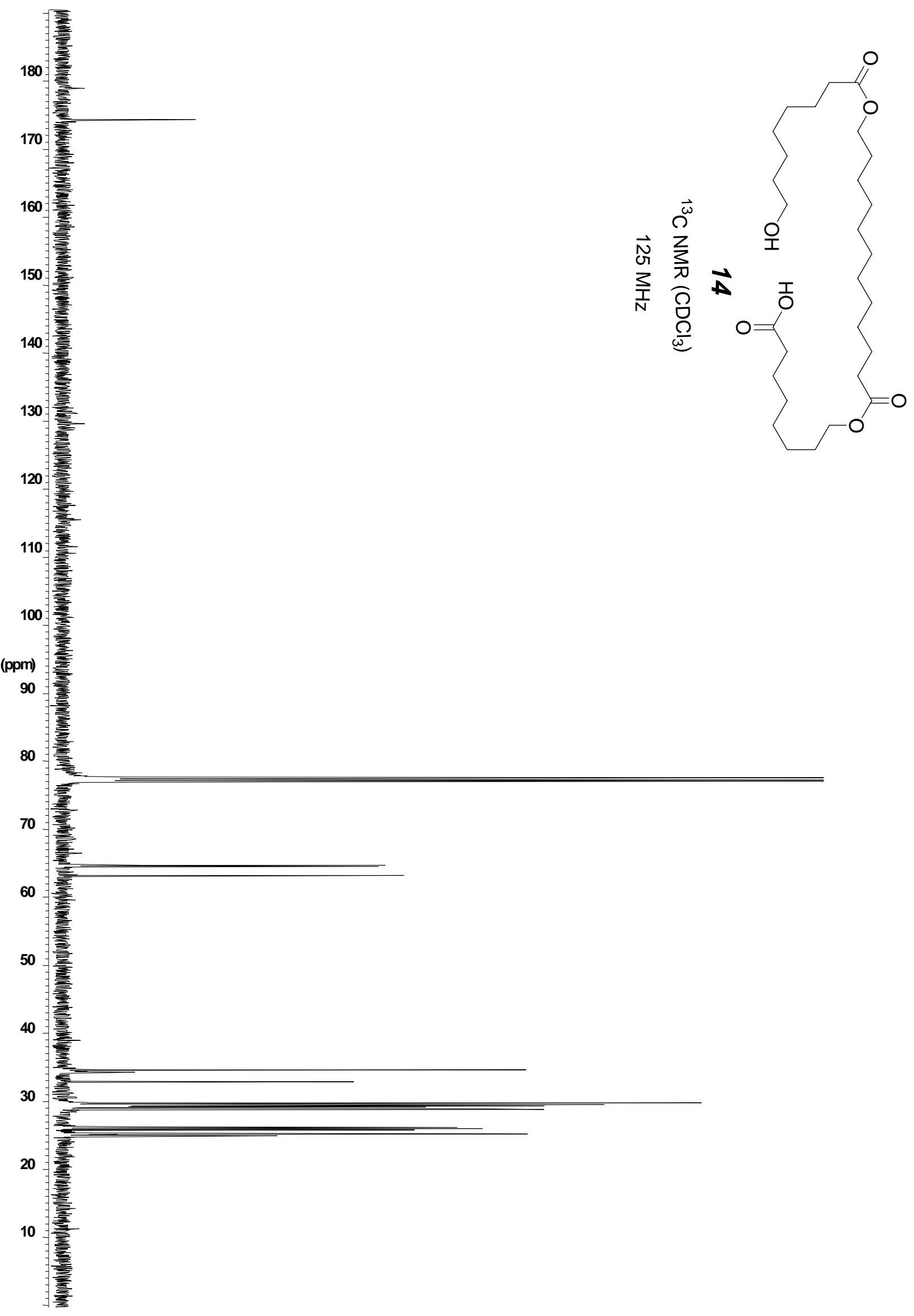




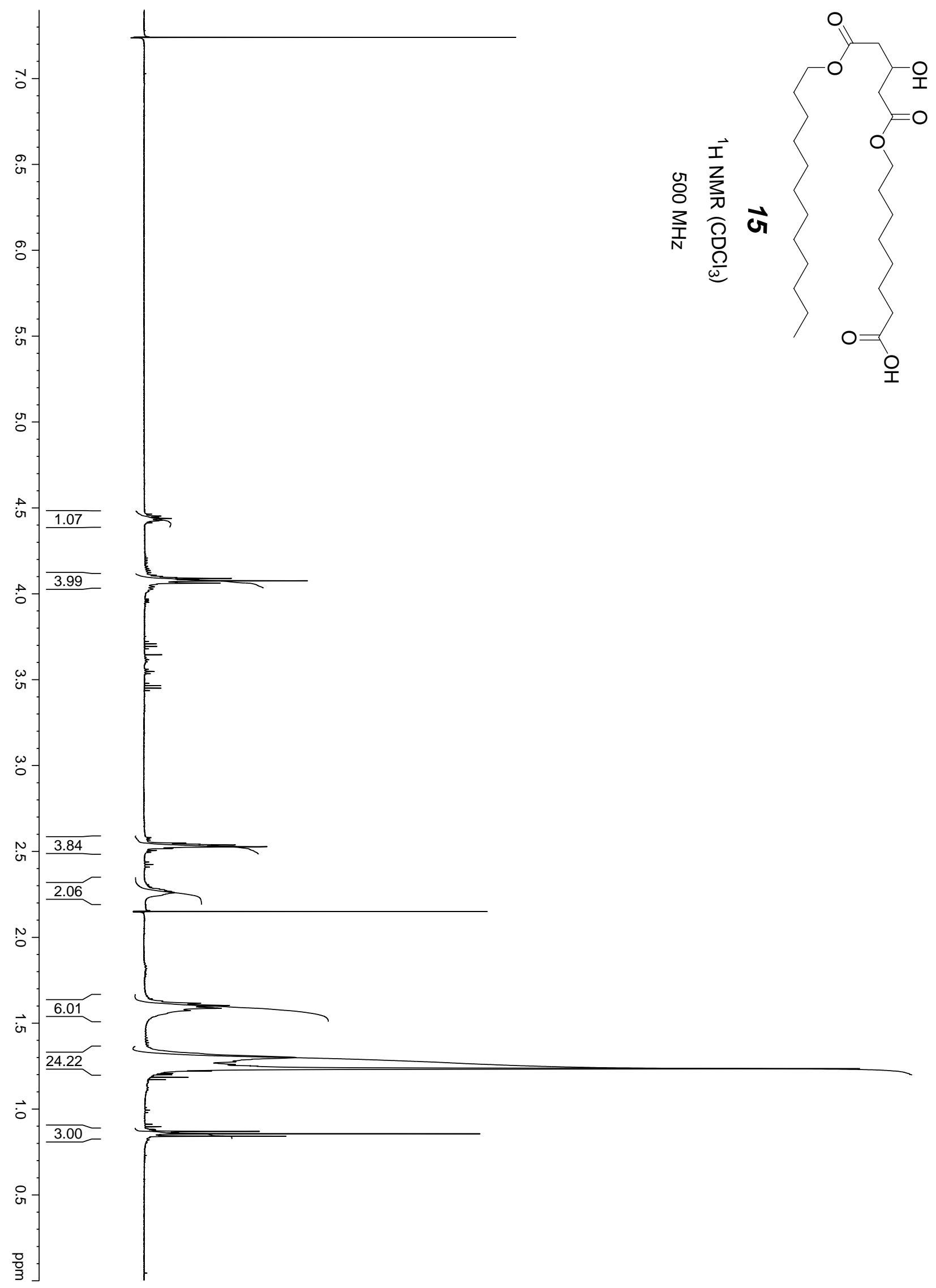




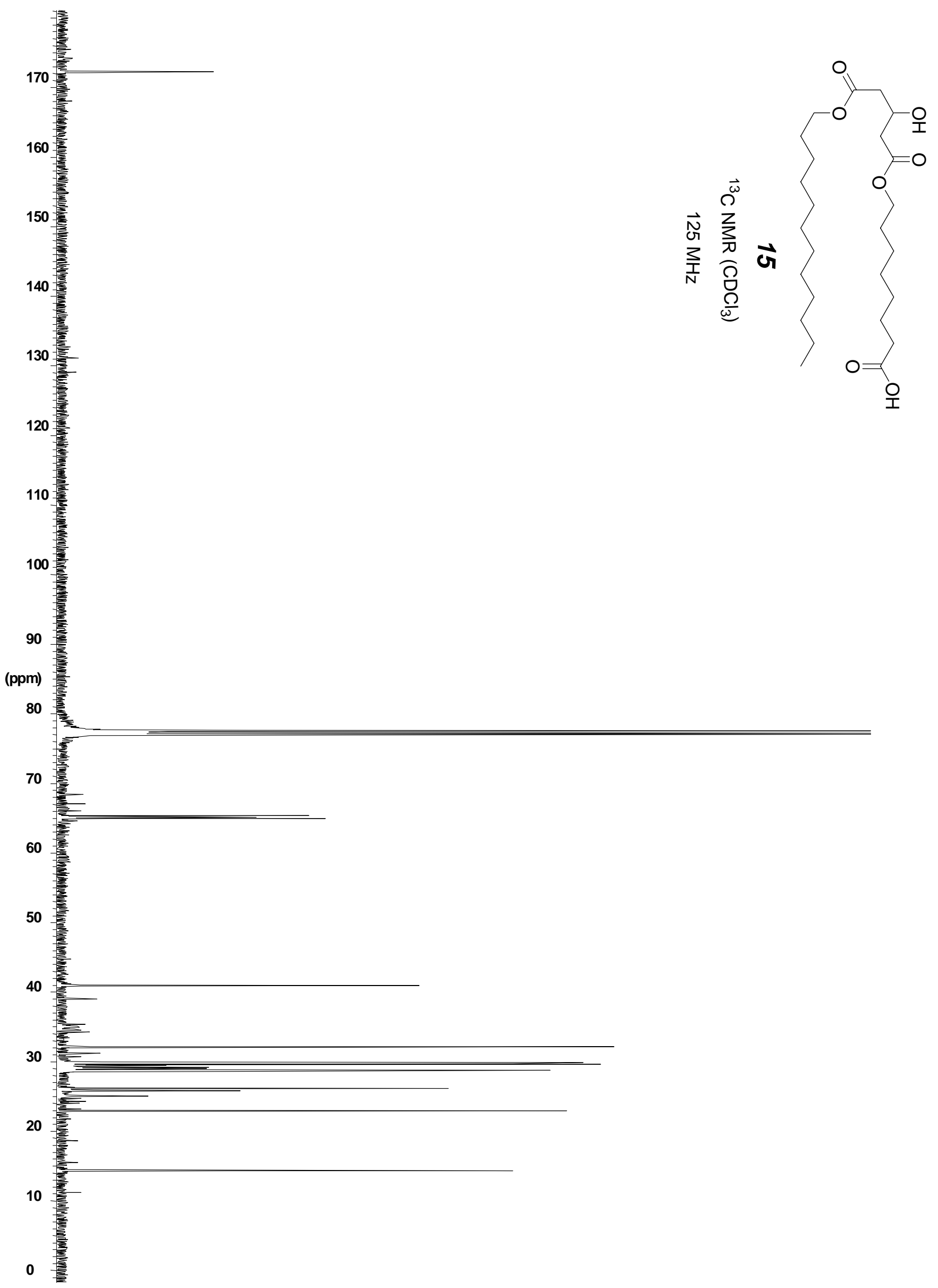




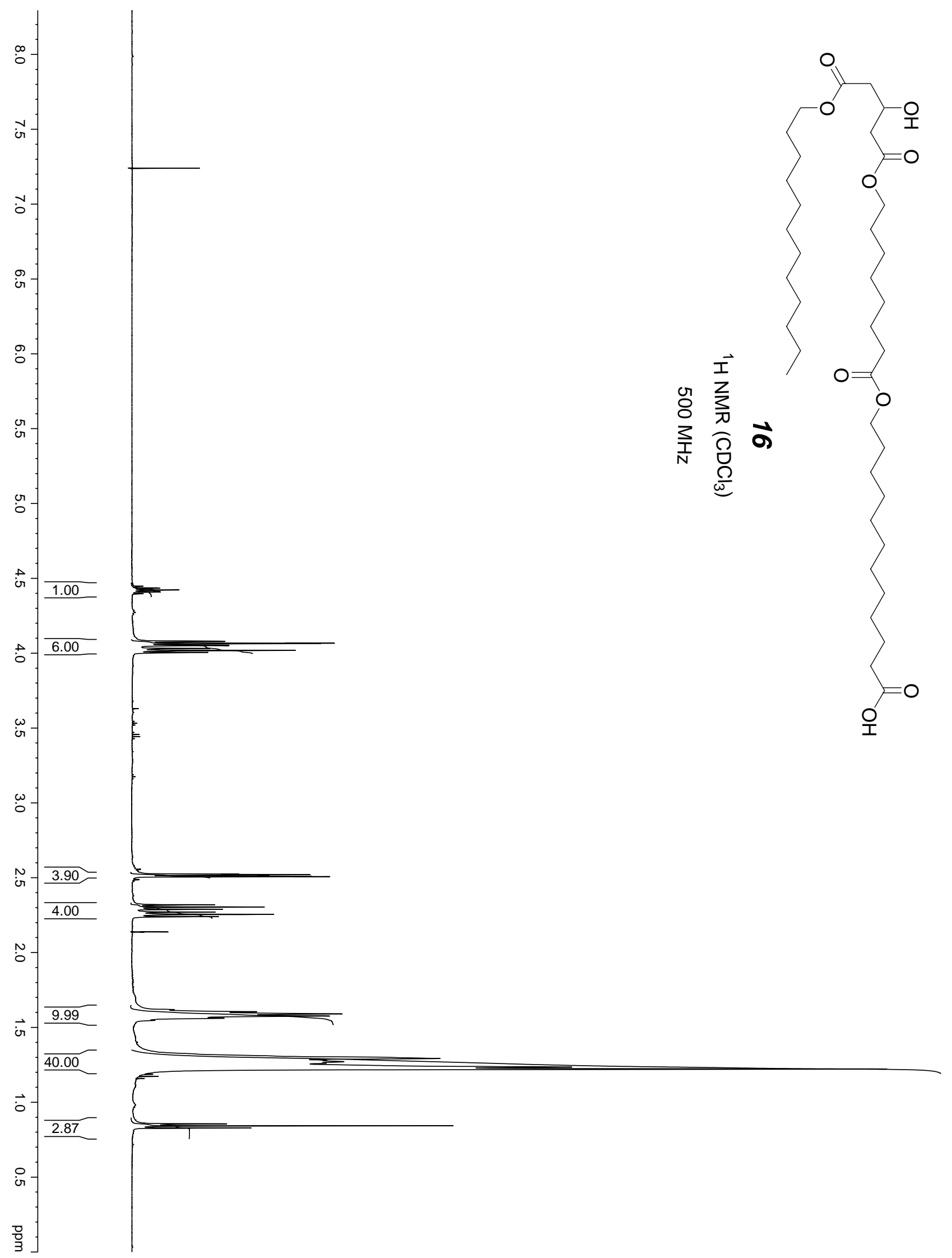




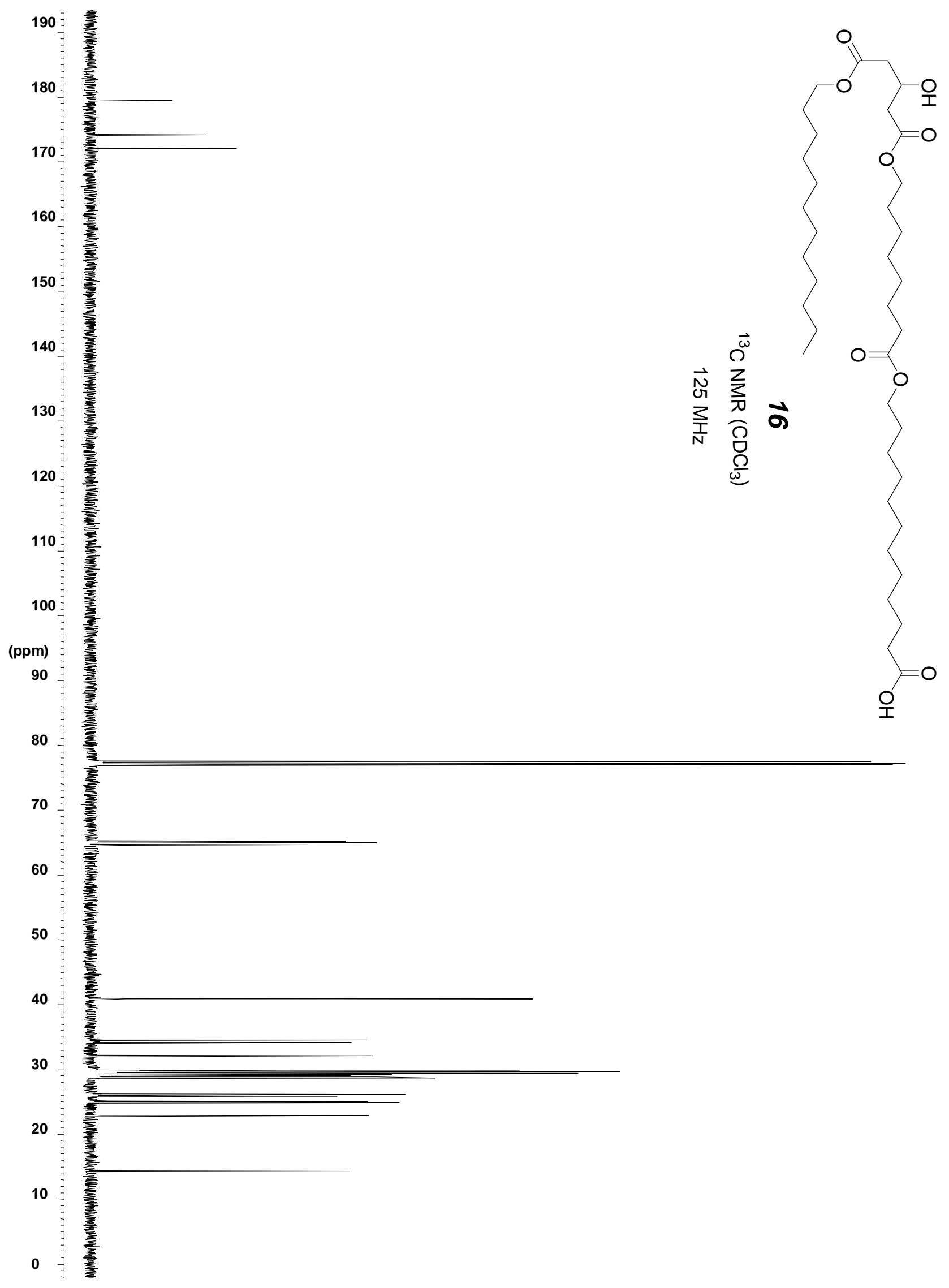




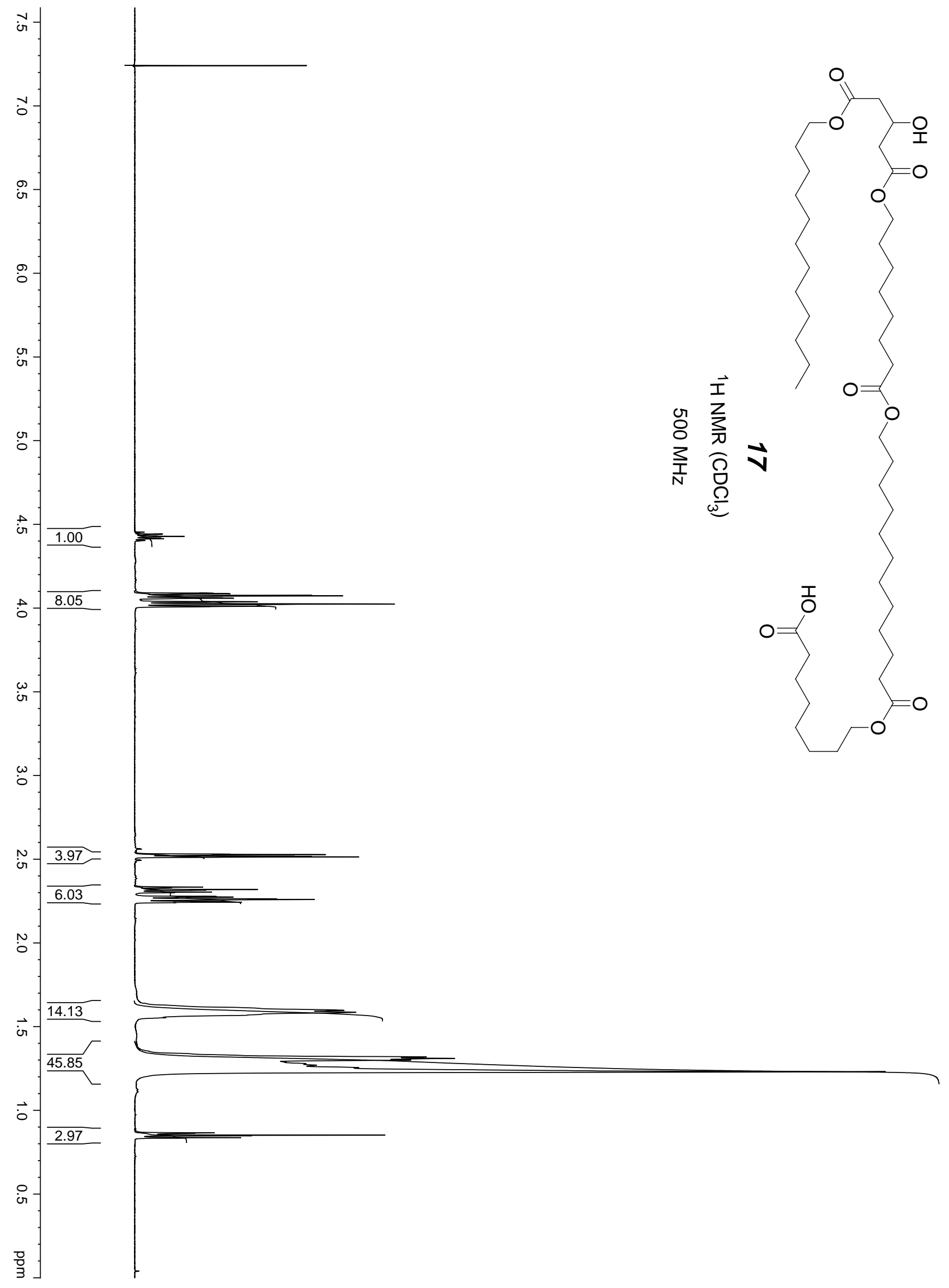




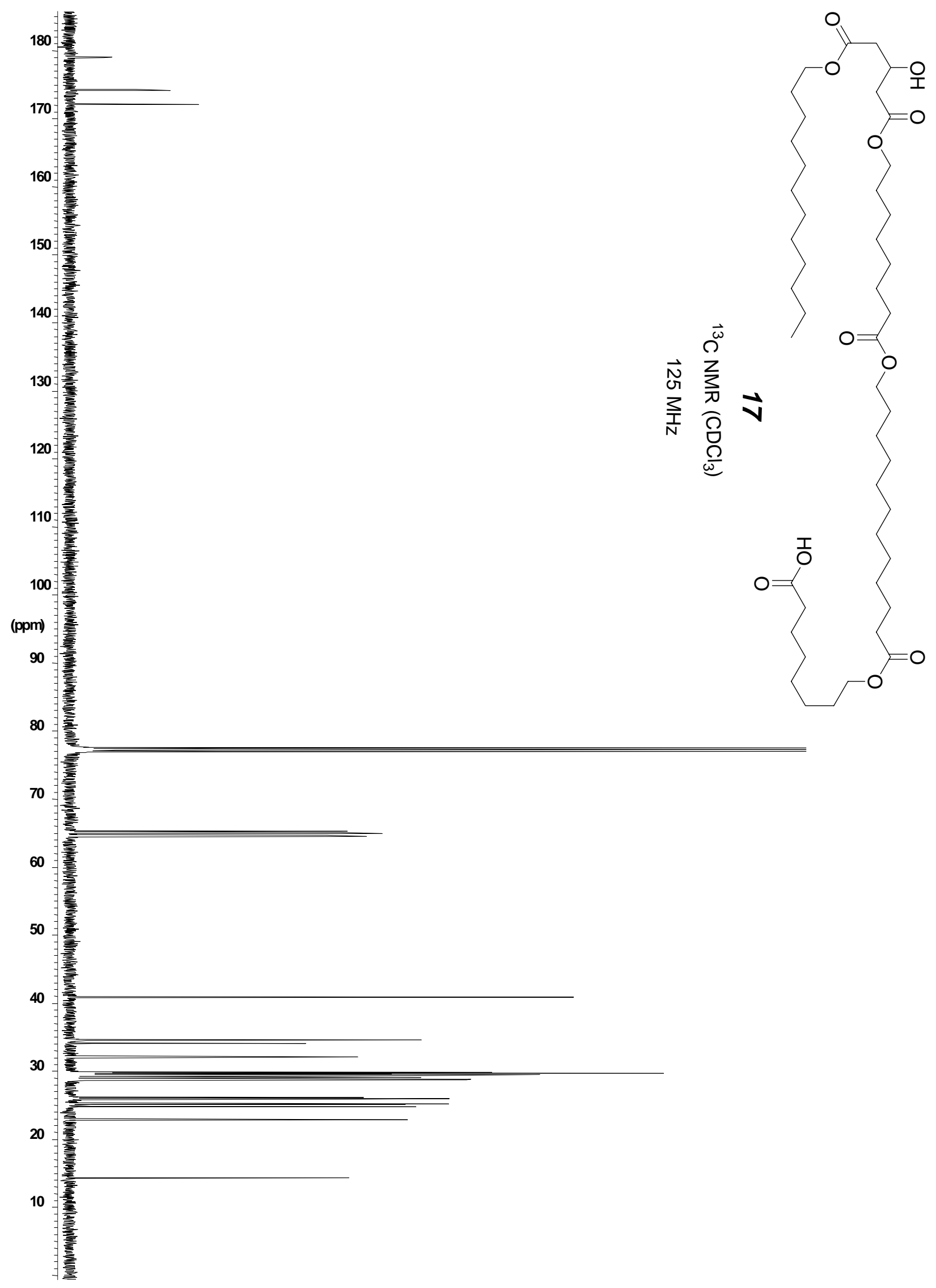




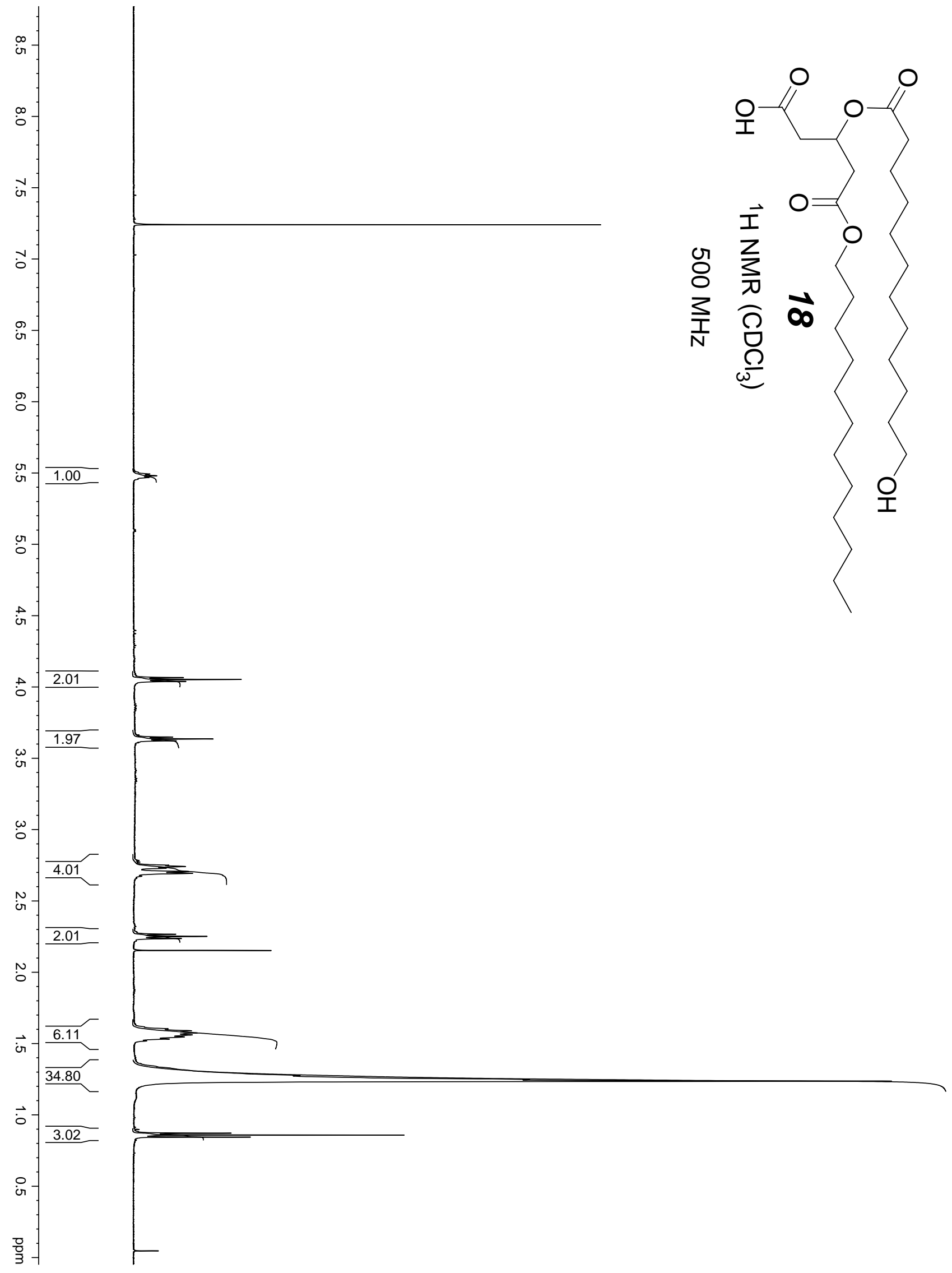




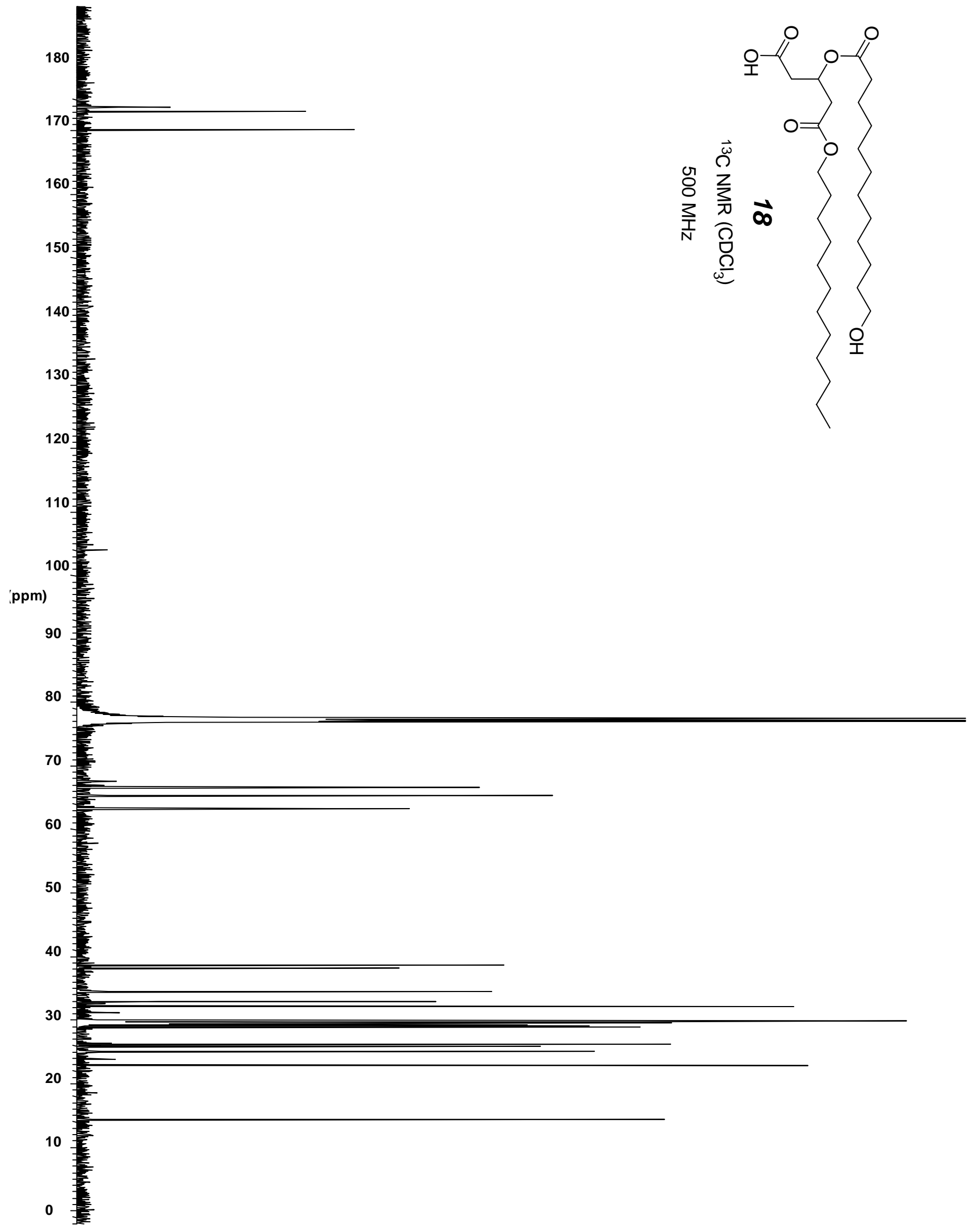




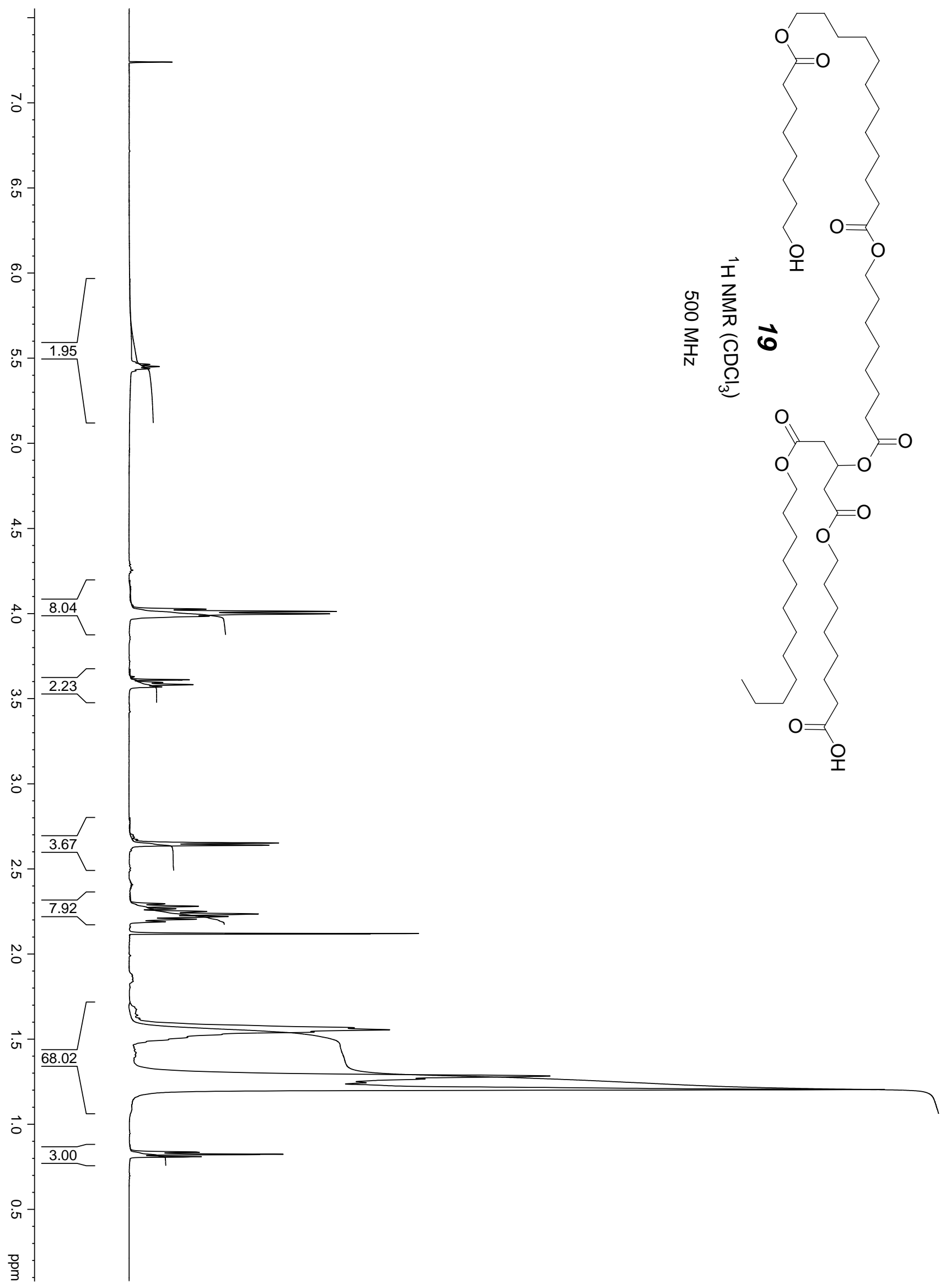




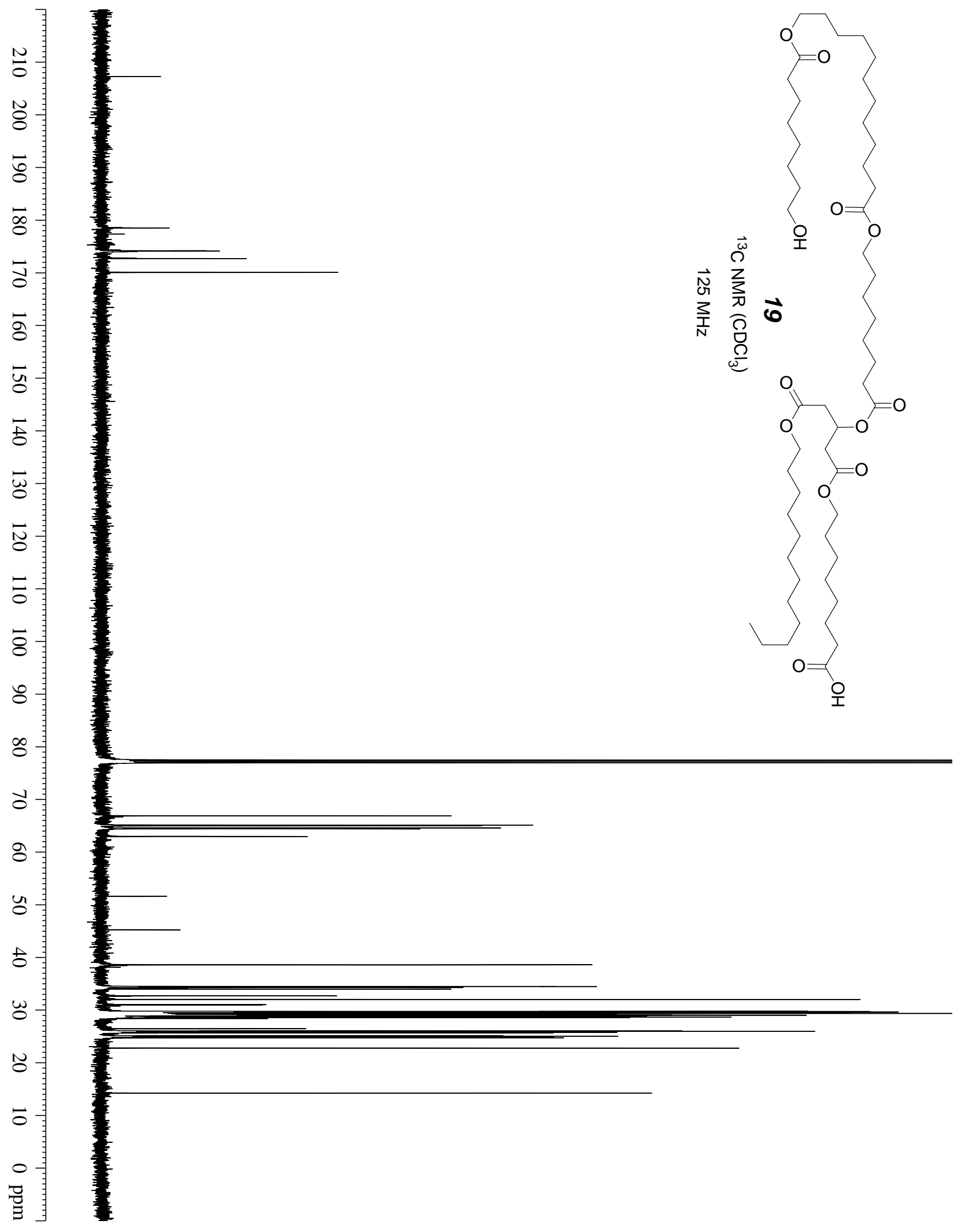




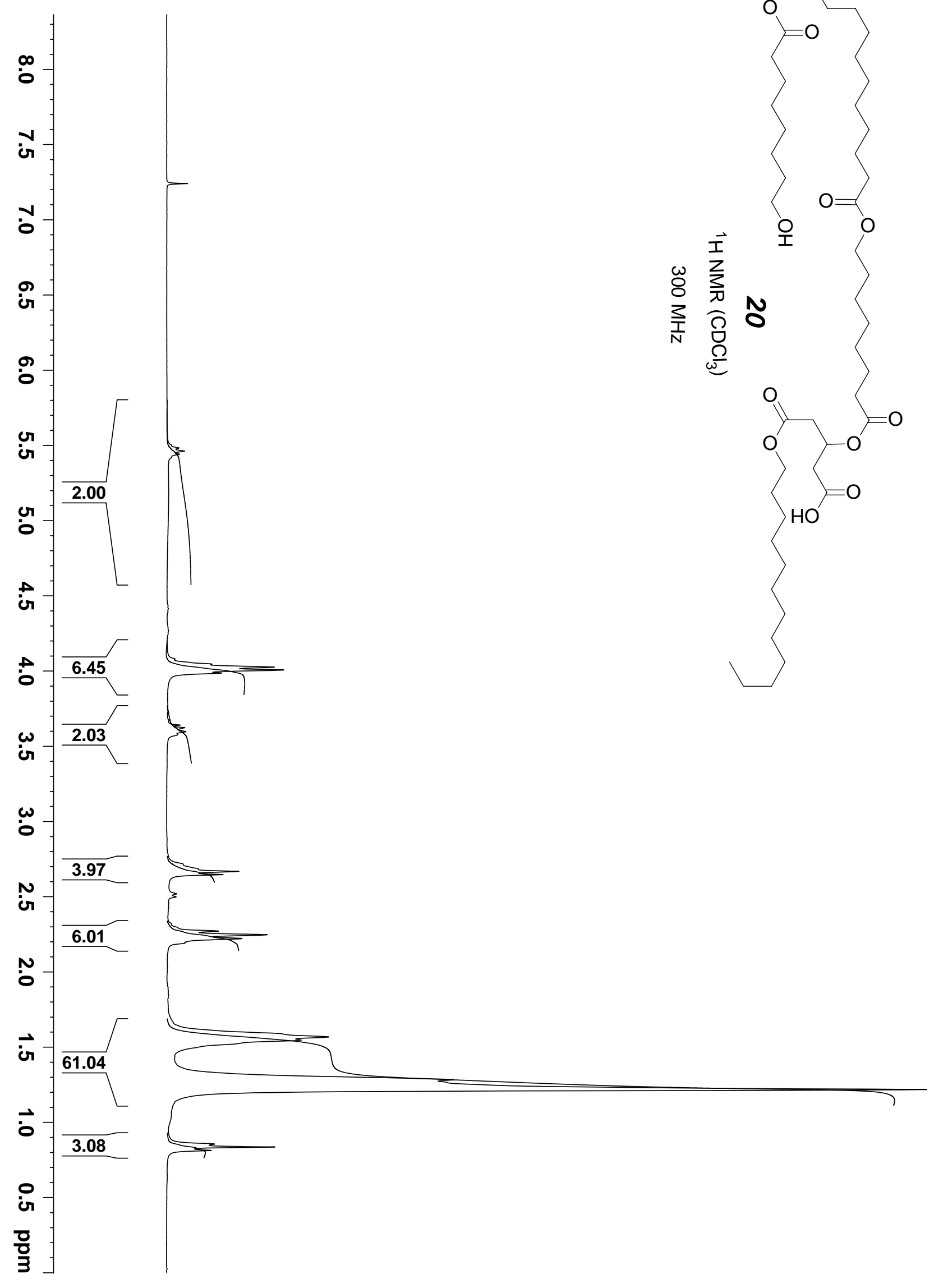




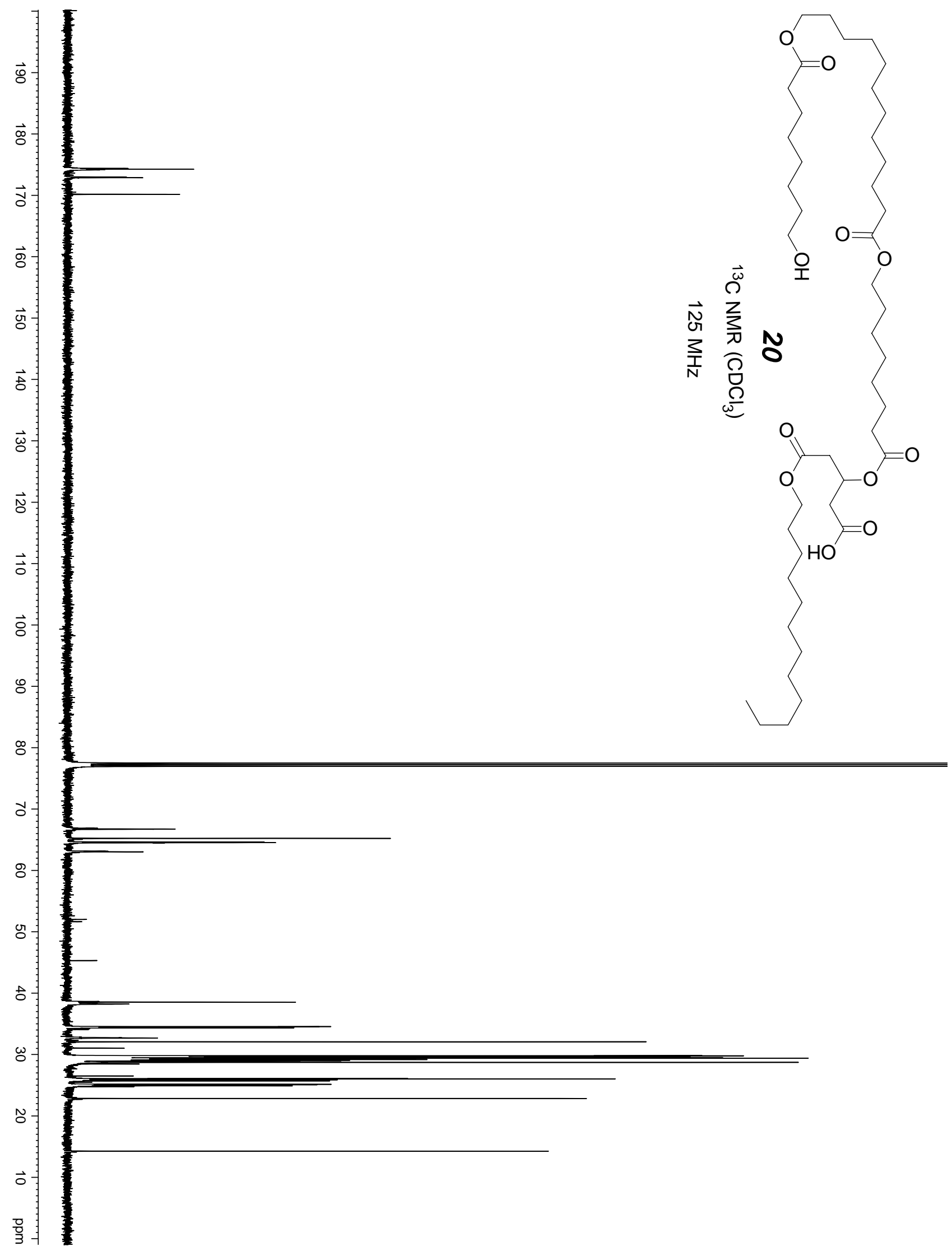

